by competent examiners. (3) Eyesight tests may be used by ignorant or unscrupulous persons as a subject of political propaganda. (4) Pandering to this spirit is rightly regarded by the men as a sign of weakness, and, instead of causing satisfaction, increases that attitude of suspicion to the employers which is so much to be deplored and leads to further and greater troubles.

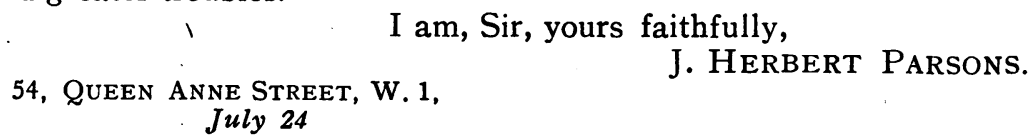

\title{
Titles of Communications
}

Only those whose business leads them to search ophthalmological or other scientific literature in pursuit of information about given subject can fully realize the difficulties caused by ambiguous titles. How many valuable contributions are cleverly hidden under such titles as "An interesting Case," "A Case for Diagnosis," and so forth. The writer well recalls a paper being submitted to him entitled, "Supposed death from Atropin," and the indignation with which his query was received when he asked if there was any doubt of the death having taken place. To be of service to readers a title should set forth, as briefly as may be, the contents of a communication, so that the nature of an article may be gathered at a glance. This is by no means always an easy task, but all titles that fail to fulfil the necessary conditions should be ruthlessly dealt with by the editor of the journal in which the article is to be published. On the other hand, there are authors who select lengthened titles, which in point of fact amount to an abstract of the contents of the communication they cover. This is cumbrous, although it is not so much to be condemned as the fault first mentioned. In fact, the briefer the title, consistent with lucidity, the better. The last fault is the omission of a title, throwing the onus of selecting one upon somebody else.

\section{ABSTRACTS}

\section{I.-SYMPATHETIC OPHTHALMITIS}

(I) Carpenter, E. R.-Some points relative to enucleation of the eyeball and sympathetic inflammation. Med. Press and Circular, November 2I, I9I7.

(I) Carpenter believes that the more conservative methods of dealing with injured eyes would in many cases be justified since the 